\title{
Identification of personality traits affecting entrepreneurial performance in the hospitality subsector: A five-factor personality model
}

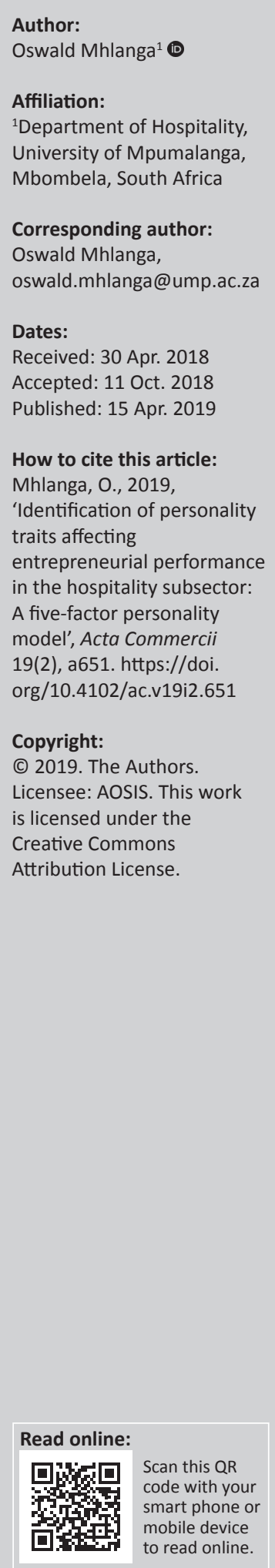

Orientation: Although tourism growth is higher relative to other industries in South Africa, the failure rate for entrepreneurs in the hospitality subsector is higher relative than other industries.

Research purpose: The aim of this research was to identify personality traits affecting entrepreneurial performance in the hospitality subsector.

Motivation for the study: By identifying the personality traits affecting entrepreneurial performance, steps can be made to identify individuals who are likely to be successful entrepreneurs.

Research design, approach and method: A random sampling method was used to select respondents. However, only entrepreneurs that employ fewer than 50 full-time employees and who had been in operation for at least 2 years were targeted. A mixed methods research design was then followed. A meeting was held with ten entrepreneurs (qualitative) to discuss the purpose of the study. Consequently, a total of 437 entrepreneurs successfully completed questionnaires (quantitative). Exploratory factor analysis was used to analyse the data.

Main findings: The findings clearly indicate that extraversion, conscientiousness and openness to experience significantly $(p<0.05)$ and positively affected the performance of entrepreneurs whilst neuroticism significantly $(p<0.05)$ and negatively affected the performances of entrepreneurs.

Practical/managerial implications: Existing entrepreneurs would do well to develop these traits or employ people with traits that complement their own to assist them in managing their enterprises. Future entrepreneurs may consider these results and decide whether, based on their personality, they are really suited to business ownership.

Contribution/value-add: The research confirms that entrepreneurial attributes differ from industry to industry and are industry specific.

Keywords: South Africa; hospitality entrepreneurs; personality traits; entrepreneurial performance; tourism.

\section{Introduction}

'Not everyone can be an entrepreneur' (Farrington 2012:383). According to Srivastava (2010), an individual's personality traits predict his or her entrepreneurial prowess, which affects entrepreneurship performance. Personality traits are complex, genetically co-determined psychophysiological characteristics of an individual manifested in a consistent way of behaving in a wide variety of situations (Said 2013). The possession of certain personal traits enables entrepreneurs to perform their roles well whilst the absence of certain traits may disable an individual from emerging as a successful entrepreneur. Given that entrepreneurial prowess is a function of personality traits, personality traits affect entrepreneurship performance (Scarborough 2011).

The relationship between personality and entrepreneurship performance is empirically supported by several meta-analyses (Martin, Julius \& Grace 2016; Thal \& Bedingfield 2010; Zhao, Seibert \& Lumpkin 2010) and personality traits are agreed to be valid predictors of entrepreneurial performance (Slavec 2014). In the extant literature, some research endeavours (see works by Barrick, Mount \& Gupta 2003; Barrick \& Mount 2005; Barringer \& Ireland 2010) argue that successful entrepreneurs are characterised by a close relationship with their owners' characteristics because of functional convergence and intuitive decision-making.

In the same line of thought, Barrick and Mount (2005) denote a holistic entrepreneurial performance approach based on personality traits. The particular trademarks of entrepreneurs elaborated by 
Zhao et al. (2010), Patel and Thatcher (2014) as well as Srivastava (2010) clearly establish a link between the entrepreneurs' personality, their behaviour and their establishments' performance. Therefore, personality traits can either constrain or encourage entrepreneurial behaviour that affects entrepreneurial performance, as clearly articulated by Farrington (2012).

According to a study by Small Enterprise Development Agency (SEDA 2018), South Africa has one of the highest failure rates of small to medium-sized enterprises (SMEs) in the world, at an estimated $75 \%$. The SEDA furthermore cites entrepreneurs in the tourism industry as one of the highest failures relative to other industries with five out of seven new small enterprises in the hospitality subsector failing within their first year of operation and $81 \%$ failing within 5 years. Mhlanga (2018a) attributes the high failure rate to the lack of identification of personality traits that affect entrepreneurial performance in the hospitality subsector. Consequently, identification of personality traits affecting entrepreneurial performance is indispensable in the hospitality subsector.

Despite the long history of controversy in relation to the personality of the entrepreneur (Weiten 2010), there is scant academic research investigating the effects of personality traits on entrepreneurial performance in the hospitality subsector (Scarborough 2011). Research papers that identify personality traits affecting entrepreneurial performance are restricted to the agricultural sector. However, studies in the agricultural sector might not be applicable to the hospitality subsector, as Said (2013) claims that the effects of personality traits on entrepreneurial performance differ from industry to industry.

Because of the importance of entrepreneurship in the hospitality subsector in South Africa, research within this context is necessary (Mhlanga 2018b). The identification of personality traits affecting entrepreneurial performance could be helpful in the hospitality subsector, where there is a preponderance of SMEs that are family-run restaurants, guesthouses, backpackers and bed and breakfasts (Mhlanga \& Tichaawa 2016). In this study, the term 'entrepreneur' is used to refer to 'hospitality entrepreneurs'.

\section{Study context}

Over the last couple of decades, tourism has been recognised as playing a significant role in global and national economies (Mhlanga 2013). According to the World Travel and Tourism Council (WTTC 2018), the tourism sector generated 108741000 jobs directly in 2016 (3.6\% of total employment) and supported 6 million net additional jobs. In total, the tourism sector generated US\$7.6 trillion (10.2\% of global gross domestic product [GDP]) and 292 million jobs in 2016, equivalent to 1 in 10 jobs in the global economy. Tourism is predicted to support over 380 million jobs by 2027 (WTTC 2018).

In 2016, the tourism sector directly contributed $2.9 \%$ to South Africa's GDP, which is an estimated ZAR
125.1 billion (Statistics South Africa [SSA] 2018). This makes the tourism sector a larger contributor than agriculture (2\% to GDP). Statistics South Africa (2018) further reports that in 2016, 1 in 23 persons were employed or worked in the tourism sector in South Africa, which is $4.4 \%$ of the total workforce in the country. This is 686596 people who were directly employed in 2016 in the sector, more than in 2015. The tourism sector's 686596 employees outnumbered the workforces of utilities (118000 employees) and mining (444000 employees). In terms of job creation, the tourism sector added 40000 net new jobs to the economy over the 5-year period from 2012 to 2016 (WTTC 2018). This is higher than the number of jobs gained in manufacturing.

The hospitality subsector is one of the six subsectors of the South African tourism industry (Culture, Arts, Tourism, Hospitality and Sports Sector Education and Training Authority 2018). The hospitality subsector can be regarded as an archetypical entrepreneurial industry accounting for approximately 4\% of South Africa's employment in 2017 in over 70000 restaurants, 11000 guesthouses, 9000 bed and breakfasts, 7000 hotels and many other types of outlets, according to SSA (2018). The hospitality subsector is therefore a critical cornerstone of the tourism industry (Mhlanga 2018b).

\section{Theoretical framework: The five- factor personality model}

The five-factor personality model is one of the most comprehensive and parsimonious personality taxonomies (Said 2013). The model is a multidimensional approach towards defining personality, through measuring openness, conscientiousness, extraversion, agreeableness and neuroticism. Each personality dimension describes a broad domain of psychological functioning that is composed from a set of more specific facets (Slavec 2014) as described in the following.

Openness to experience characterises someone who is open to novel experiences and ideas and who is imaginative, innovative and reflective. It describes the breadth, depth, originality and complexity of an individual's mental and experiential life (Nadkarni \& Herrmann 2010). Openness to experience is correlated to being broad-minded, imaginative, sensitive, intelligent, creative, curious, cultured and original (Said 2013). People high in openness to experience are highly adaptable to change and seem to thrive in situations that require flexibility and are highly motivated to learn new skills. Their open-mindedness leads them to seek a lot of information and feedback about how they are doing and to build relationships.

Conscientiousness describes socially prescribed impulse control that facilitates task- and goal-directed behaviour, such as thinking before acting, delaying gratification, following norms and rules, and planning, organising and prioritising tasks. Nadkarni and Herrmann (2010) argue that people who are conscientious are hardworking and achievement oriented and persevere in their endeavours. 
TABLE 1: The five-factor personality model.

\begin{tabular}{lll}
\hline Factor & Traits & Description \\
\hline 1 & $\begin{array}{l}\text { Openness to } \\
\text { experience }\end{array}$ & $\begin{array}{l}\text { Broad-minded, imaginative, sensitive, intelligent, } \\
\text { curious, cultured, original and creative. }\end{array}$ \\
\hline 2 & Conscientiousness & $\begin{array}{l}\text { Organised, systematic, punctual, purposeful, } \\
\text { determined and dependable. }\end{array}$ \\
3 & Extraversion & $\begin{array}{l}\text { Friendly, energetic, warm, assertive, cheerful, } \\
\text { outspoken and sociable. }\end{array}$ \\
4 & Agreeableness & $\begin{array}{l}\text { Courteous, forgiving, soft-hearted, affable, tolerant, } \\
\text { trusting and kind. }\end{array}$ \\
\hline 5 & Neuroticism & $\begin{array}{l}\text { Anxious, aggressive, temperamental, insecure, } \\
\text { moody and depressed. }\end{array}$ \\
\hline
\end{tabular}

Therefore, individuals who score high on conscientiousness are orderly and hardworking and have a tendency to be self-disciplined, act dutifully, aim for achievement and plan ahead rather than act spontaneously (Barrick et al. 2003).

Extraversion includes characteristics such as sociability, talkativeness, assertiveness and ambition. According to Erdheim, Wang and Zickar (2006), extraverted individuals are associated with emotional commitment compared to the other five personality traits. Individuals high in extraversion are described as outgoing, gregarious, optimistic and upbeat, as well as energetic, enthusiastic and adventurous (Weiten 2010). People with extraversion traits are friendly, energetic, warm, assertive, cheerful, outspoken and talkative (Kickul \& Neuman 2000).

Agreeableness includes traits such as being courteous, flexible, trusting, good-natured, cooperative, forgiving, soft-hearted and tolerant (Barrick \& Mount 2005). It contrasts a prosocial and communal orientation towards others with antagonism and includes traits such as altruism, tender-mindedness, trust and modesty. Agreeableness represents the tendency to be altruistic (empathetic, kind and gentle) and compliant (modest, having a values affiliation and avoiding conflict). It has also been labelled as likeability or friendliness and includes traits such as being affectionate, generous and sympathetic, as well as modest and straightforward (Weiten 2010).

Neuroticism (or emotional instability) is one of those traits that can be labelled as a 'dark' or 'contrary feelings' personality trait. It is a propensity towards emotional instability including experiencing fear, worry, insecurity, moodiness, anger, anxiety, hostility, depression, impulsiveness, melancholy and apprehension (Zhao et al. 2010). It reflects the capacity of an individual to adjust their emotional state to the demands of the situation and being able to remain calm and balanced when faced with adversities and stressful situations (Amir et al. 2014). Neurotic individuals are prone to mood swings and are emotionally unstable, highly excitable and self-conscious (Weiten 2010). Table 1 summarises the five-factor personality model.

\section{Literature review}

Anecdotal evidence establishes the link between personality traits and entrepreneurial performance. Schröder, Schmitt and Arnaud (2011) investigated the relationship between personality traits and entrepreneurial performance in the retail sector and found a negative correlation between agreeableness and entrepreneurial performance. According to
Schröder et al. (2011), altruistic tendencies makes agreeable individuals unequipped for arranging testing bargains and affecting others to accomplish business objectives. In their study, Martin et al. (2016) used a multiple regression approach to depict the relationship between personality traits and entrepreneurial performance in the manufacturing sector and concluded that agreeableness and extraversion positively affected entrepreneurial performance whilst neuroticism negatively affected entrepreneurial performance. However, metaanalytical evidence by Zhao et al. (2010) in the construction sector points out that openness, conscientiousness and extraversion positively affect entrepreneurial performance. By contrast, neuroticism is detrimental to entrepreneurial performance and agreeableness has no effect. According to Zhao et al. (2010), neuroticism has a tendency to reduce risk-taking inclination, thus reducing the willingness to persist in business.

In another study, Leutner et al. (2014) examined the relationship between personality traits and entrepreneurial performance in the retail sector and found a positive correlation between extraversion and entrepreneurial performance and a negative relationship between conscientiousness and entrepreneurial performance. According to Leutner et al. (2014), entrepreneurs who are extraverted are less likely to fail, as they tend to strive for higher sales profits. This is because of the fact that higher extraversion raises the sensitivity for rewards. Leutner et al. (2014) further noted that among the extraversion dimensions, being sociable had the highest and most positive effect on performance. Duval, Silvia and Lalwan (2012) found that extraversion, conscientiousness and openness to experience positively affected entrepreneurial performance in the transport industry. According to Duval et al. (2012), entrepreneurs with these traits are likely to be successful in small businesses because of their creativity prowess, which highly and positively influences entrepreneurial performance.

Nadkarni and Herrmann (2010) evaluated the effects of personality traits on entrepreneurial performance in the textile industry and found that extraversion, openness to experience and emotional stability significantly and positively affected entrepreneurial performance whilst conscientiousness significantly and negatively affected entrepreneurial performance. Nadkarni and Herrmann (2010) concluded that very high levels of conscientiousness may result in inertia and adverse performance, whereas very low levels of conscientiousness may create instability and uncertainty for entrepreneurs. In contrast, Thal and Bedingfield (2010) found no clear link between extraversion and entrepreneurial performance in the medical industry but a positive relationship between agreeableness and entrepreneurial performance. These authors argue that agreeableness has an effect on performance as agreeable entrepreneurs can command respect, trust and cooperation.

Slavec (2014) explored the relationship between personality traits and entrepreneurial performance in the petroleum industry and found a positive relationship between the three dimensions of openness to experience, namely independence, 
creativity and curiosity, and entrepreneurial performance. In another study, Ciavarella et al. (2004) found a negative relationship between the entrepreneurs' extraversion, neuroticism and agreeableness and entrepreneurial performance in the marketing industry. Ciavarella et al. (2004) noted that among the neurotic dimensions, moodiness had the highest and most negative effect on performance. Kaczmarek and Kaczmarek-Kurczak (2016) also found that neuroticism significantly affected entrepreneurial performance in the telecommunications industry because of emotional instability. Kaczmarek and Kaczmarek-Kurczak (2016) noted that among the neurotic dimensions, depression had the highest and most negative effect on performance.

Using a compilation of the employment history data of 2839 individuals from 1957 to 2004, Patel and Thatcher (2014) investigated the effects of personality traits on entrepreneurial performance in the manufacturing industry and found that openness to experience, self-governance and tenacious goals positively affected entrepreneurial performance. According to Patel and Thatcher (2014), individuals with these traits would probably address existing methods for doing business, which in addition to their intellectual capacities results in recognisable new opportunities.

Brandstätter (2011) used a meta-analysis technique to test the relationship between agreeableness and entrepreneurial performance and found a negative relationship between the two. According to Brandstätter (2011) an agreeable person is more easily manipulated and influenced by others for their gain. Entrepreneurs who are agreeable are unlikely to compete for limited resources or are focused on avoiding conflict and confrontations and become less dominant, less independent and less competitive. Unfortunately, none of these studies can be directly applied to the context of the hospitality subsector, hence the need to conduct this study. Therefore, the effects of personality traits as an explanatory factor in entrepreneurial performance in the hospitality subsector merit some debate.

\section{Research methodology}

A list of registered entrepreneurs in the Eastern Cape province of South Africa was obtained from the SEDA in East London. Entrepreneurs who had established their own businesses in the hospitality subsector in the Eastern Cape were taken as the population of the study. A random sampling method was used to select respondents from a list of active registered hospitality entrepreneurs (in the Eastern Cape province in South Africa) with SEDA.

A mixed-methods research design (McMillan \& Schumacher 2010) was followed. To incorporate content validity, a tentative meeting (qualitative) was scheduled by the researcher with 10 entrepreneurs to discuss the purpose of the study and for their inputs on the study. These 10 entrepreneurs were not included in the main study. Content validity connotes the extent to which a measurement instrument is a representative sample of the content area being measured (Leedy \& Ormrod 2013). After the meeting, a research questionnaire (quantitative) was designed and distributed to entrepreneurs for data collection.

After the meeting, two suggestions were made by entrepreneurs. These suggestions guided the research design of the study. Initially, the entrepreneurs suggested that only entrepreneurs that employ fewer than 50 full-time employees and who have been in operation for at least 2 years should be targeted. Secondly, the entrepreneurs suggested that the questionnaire should not be too long. They proposed that the questionnaire should be less than three pages in length and easy to comprehend.

To incorporate face validity, a self-administered questionnaire based on the five-factor personality model developed by Norman (1963) and with reference to questionnaires used in previous studies was customised to address the objectives and setting of the study. Face validity is the extent to which, on the surface, an instrument looks like it is measuring a particular characteristic (Leedy \& Ormrod 2013). Using measures that have been used in previous research also ensured the reliability of the questionnaire. Leedy and Ormrod (2013) posit that one way to help ensure reliability in getting information from people is to use measures that have proven their reliability in previous research.

Entrepreneurs were requested to rate the effects of personality traits on entrepreneurial performance. Norman's (1963) fivefactor personality model (conscientiousness, agreeableness, openness to experience, extraversion and neuroticism) was used as an exogenous variable because some research endeavours (Barrick et al. 2003; Farrington 2012; Scarborough 2011; Srivastava 2010) identify these five dimensions as the most important personality traits that affect entrepreneurial performance. Entrepreneurial performance was treated as an independent variable. This method of testing the relationship between personality traits and entrepreneurial performance is comparable to the technique used by Barrick et al. (2003), where they also used personality traits as exogenous variables and entrepreneurial performance as an independent variable.

The questionnaire included 34 questions based on the fivefactor personality model, measured using a five-point Likert scale. The questions included seven items to measure the construct of agreeableness, seven to measure the construct of extraversion, six to measure the construct of neuroticism, eight to measure the construct of openness to experience and six to measure the construct of conscientiousness. The five response alternatives for measuring the effects of personality traits (independent variable) on entrepreneurial performance (dependent variable) ranged from 'very unimportant' (1), 'unimportant' (2), 'neither unimportant nor important' (3) and 'important' (4) to 'very important' (5).

The sample size was chosen based on a table that was formulated to determine how large a randomly chosen sample, from a given finite population, should be, as proposed by Isaac and Michael (1981). According to Isaac and Michael, the 
sample size should be about $10 \%$ of the size of the population. Therefore, a sample size of 437 respondents was deemed appropriate and consequently used for the study.

An email was sent to each entrepreneur asking the respondent to complete the questionnaire. The researcher explained the purpose of the survey, indicated that participation was voluntary and requested the entrepreneur to complete the questionnaire voluntarily. Data were collected between September, October and November 2017. Exploratory factor analysis was used to reduce the data to the main constructs of the theoretical model using the Statistical Package for Social Sciences (SPSS) software version 23.

\section{Ethical considerations}

Participation in the study was voluntary, and written permission was obtained from entrepreneurs whilst ethical clearance was obtained from Cape Peninsula University of Technology (ethical clearance number: 2017 FBREC 424). Before the survey was performed, the questionnaire was tested on a group of eight randomly selected entrepreneurs, who were not included in the final sample. No changes were made to the questionnaire. The questionnaires were sent to a random sample of 582 entrepreneurs. However, 28 questionnaires were incomplete, leaving a total of 437 fully completed questionnaires.

\section{Findings}

Accordingly, Table 2 shows the results and the variable mean scores and standard deviations for personality attributes affecting entrepreneurial performance.

Table 2 depicts the mean scores and standard deviations calculated for the effects of personality attributes on the performance of hospitality entrepreneurs. An initial glance at the data reveals that the effect of each attribute varied from 1.39 for depression (V34) to 4.91 for sociable (V21), with 5 being the highest possible score. Standard deviations between 0.40 (systematic) and 1.26 (creative) were calculated.

Table 2 further depicts that creativity (V8) highly affected positively the performance of coffee shops (4.88), bed and breakfasts (4.90), guesthouses (4.85) and lodges (4.89), whilst

TABLE 2: Means and standard deviations for the personality attributes affecting entrepreneurial performance.

\begin{tabular}{|c|c|c|c|c|c|c|c|c|c|c|c|c|c|}
\hline \multirow[t]{3}{*}{ Code } & \multirow{3}{*}{$\begin{array}{l}\text { Personality } \\
\text { attribute }\end{array}$} & \multicolumn{12}{|c|}{ Hospitality entrepreneurship performances } \\
\hline & & \multicolumn{2}{|c|}{ Restaurants } & \multicolumn{2}{|c|}{ Coffee shops } & \multicolumn{2}{|c|}{$\mathrm{B}$ and $\mathrm{Bs} \uparrow$} & \multicolumn{2}{|c|}{ Guesthouses } & \multicolumn{2}{|c|}{ Lodges } & \multicolumn{2}{|c|}{ Hotels } \\
\hline & & M & SD & M & SD & M & SD & $M$ & SD & M & SD & M & SD \\
\hline V1 & Broad-minded & 4.73 & 0.68 & 4.72 & 0.73 & 4.69 & 0.65 & 4.70 & 0.56 & 4.76 & 0.60 & 4.75 & 0.82 \\
\hline V2 & Imaginative & 4.86 & 0.57 & 4.81 & 1.16 & 4.76 & 0.52 & 4.73 & 0.44 & 4.65 & 0.53 & 4.50 & 0.59 \\
\hline V3 & Sensitive & 4.38 & 0.71 & 4.52 & 0.62 & 4.66 & 1.04 & 4.48 & 0.85 & 4.49 & 0.47 & 4.67 & 0.53 \\
\hline V4 & Intelligent & 4.51 & 0.83 & 4.67 & 0.46 & 4.54 & 0.83 & 4.65 & 0.61 & 4.30 & 0.62 & 4.59 & 0.77 \\
\hline V5 & Curious & 4.28 & 0.55 & 4.20 & 0.61 & 4.44 & 0.76 & 4.39 & 0.98 & 4.29 & 0.58 & 4.30 & 0.60 \\
\hline V6 & Cultured & 4.32 & 0.79 & 4.35 & 0.85 & 4.23 & 0.91 & 4.28 & 0.50 & 4.21 & 0.65 & 4.22 & 0.81 \\
\hline V7 & Original & 4.20 & 0.60 & 4.17 & 0.54 & 4.08 & 0.68 & 4.50 & 0.72 & 4.47 & 0.56 & 4.46 & 0.72 \\
\hline V8 & Creative & 4.87 & 0.52 & 4.88 & 0.66 & 4.90 & 0.67 & 4.85 & 0.83 & 4.89 & 0.72 & 4.78 & 1.26 \\
\hline V9 & Organised & 4.14 & 0.42 & 4.08 & 0.72 & 4.20 & 0.84 & 4.21 & 0.66 & 4.49 & 0.80 & 4.26 & 0.95 \\
\hline V10 & Systematic & 4.36 & 0.71 & 4.24 & 0.95 & 4.29 & 0.42 & 4.18 & 0.59 & 4.41 & 0.40 & 4.35 & 0.64 \\
\hline V11 & Punctual & 4.09 & 1.13 & 3.86 & 0.51 & 4.02 & 0.60 & 3.73 & 1.06 & 4.11 & 0.57 & 4.03 & 0.93 \\
\hline V12 & Purposeful & 4.75 & 0.96 & 4.71 & 0.77 & 4.82 & 0.73 & 4.70 & 0.52 & 4.78 & 0.63 & 4.54 & 1.08 \\
\hline V13 & Determined & 4.61 & 0.64 & 4.52 & 0.81 & 4.59 & 0.85 & 4.52 & 0.58 & 4.66 & 0.71 & 4.53 & 0.76 \\
\hline V14 & Dependable & 4.78 & 0.53 & 4.84 & 0.90 & 4.71 & 0.66 & 4.82 & 0.69 & 4.80 & 0.59 & 4.67 & 0.87 \\
\hline V15 & Friendly & 4.91 & 0.88 & 4.79 & 0.42 & 4.82 & 0.59 & 4.75 & 0.81 & 4.83 & 0.67 & 4.84 & 0.71 \\
\hline V16 & Energetic & 4.78 & 0.70 & 4.85 & 0.55 & 4.80 & 0.97 & 4.83 & 0.70 & 4.85 & 0.73 & 4.61 & 0.90 \\
\hline V17 & Warm & 4.63 & 0.95 & 4.77 & 0.64 & 4.72 & 0.62 & 4.58 & 1.06 & 4.79 & 0.66 & 4.76 & 0.82 \\
\hline V18 & Assertive & 4.75 & 1.02 & 4.43 & 0.81 & 4.53 & 0.71 & 4.47 & 0.64 & 4.65 & 0.87 & 4.59 & 1.01 \\
\hline V19 & Cheerful & 4.72 & 0.67 & 4.34 & 0.70 & 4.56 & 0.56 & 4.55 & 0.41 & 4.63 & 0.51 & 4.56 & 0.79 \\
\hline V20 & Outspoken & 4.89 & 0.51 & 4.82 & 0.61 & 4.85 & 0.84 & 4.76 & 0.89 & 4.78 & 0.84 & 4.77 & 0.63 \\
\hline V21 & Sociable & 4.91 & 0.95 & 4.86 & 0.57 & 4.84 & 0.66 & 4.79 & 0.75 & 4.86 & 0.56 & 4.85 & 0.80 \\
\hline V22 & Courteous & 4.66 & 0.58 & 4.38 & 0.96 & 4.54 & 0.48 & 4.50 & 0.57 & 4.71 & 0.50 & 4.68 & 0.88 \\
\hline V23 & Forgiving & 3.73 & 0.91 & 3.68 & 0.65 & 3.99 & 0.83 & 3.72 & 0.46 & 3.56 & 0.68 & 3.60 & 0.75 \\
\hline V24 & Soft-hearted & 3.55 & 0.64 & 3.46 & 0.77 & 3.50 & 0.71 & 3.29 & 0.57 & 3.68 & 0.56 & 3.28 & 1.05 \\
\hline V25 & Affable & 3.47 & 0.53 & 3.29 & 0.99 & 3.74 & 0.95 & 3.12 & 0.64 & 3.59 & 0.69 & 2.86 & 0.97 \\
\hline V26 & Tolerant & 3.36 & 0.86 & 3.70 & 1.05 & 3.15 & 0.51 & 3.05 & 0.77 & 3.44 & 0.80 & 3.50 & 0.83 \\
\hline V27 & Trusting & 3.88 & 0.76 & 3.83 & 0.56 & 3.40 & 0.64 & 3.26 & 0.82 & 3.19 & 0.57 & 2.49 & 0.60 \\
\hline V28 & Kind & 3.89 & 1.10 & 3.52 & 0.46 & 3.08 & 0.68 & 3.70 & 0.78 & 3.26 & 0.74 & 3.44 & 1.09 \\
\hline V29 & Anxious & 4.52 & 0.59 & 4.08 & 0.55 & 4.26 & 0.76 & 3.85 & 0.66 & 3.20 & 0.90 & 3.51 & 0.61 \\
\hline V30 & Aggressive & 2.47 & 0.89 & 2.89 & 0.68 & 2.56 & 0.62 & 3.76 & 0.52 & 2.64 & 0.65 & 2.34 & 0.78 \\
\hline V31 & Temperamental & 3.02 & 0.62 & 2.64 & 0.87 & 2.23 & 0.60 & 2.15 & 0.44 & 2.17 & 0.82 & 3.03 & 1.13 \\
\hline V32 & Insecure & 3.61 & 0.74 & 3.22 & 0.72 & 3.31 & 0.87 & 2.79 & 0.57 & 3.19 & 0.64 & 3.19 & 0.59 \\
\hline V33 & Moody & 1.68 & 0.55 & 1.70 & 0.59 & 1.56 & 0.83 & 2.08 & 0.75 & 1.44 & 0.73 & 1.86 & 0.66 \\
\hline V34 & Depressed & 1.42 & 0.88 & 1.35 & 0.70 & 1.63 & 0.58 & 1.62 & 0.79 & 1.93 & 0.88 & 1.39 & 0.52 \\
\hline Overall & & 4.11 & 0.73 & 4.03 & 0.71 & 4.03 & 0.71 & 4.01 & 0.68 & 4.02 & 0.66 & 3.97 & 0.81 \\
\hline
\end{tabular}

M, mean; SD, standard deviation.

$\dagger, \mathrm{A}$ bed and breakfast is a small lodging establishment that offers overnight accommodation and breakfast and typically has between four and eleven rooms, with six being the average. 
being sociable (V21) highly affected positively the performance of restaurants (4.91) and hotels (4.85). These findings on creativity (a dimension of openness to experience) and being sociable (a dimension of extraversion) concur with previous literature (Duval et al. 2012; Leutner et al. 2014; Slavec 2014) that creativity and being sociable positively affects entrepreneurial performance. Table 2 also depicts that depression and moodiness (dimensions of neuroticism) negatively affected entrepreneurial performance. These findings support previous findings (Ciavarella et al. 2004; Kaczmarek \& Kaczmarek-Kurczak 2016) that depression and moodiness negatively affects entrepreneurial performance.

In order to determine whether the personality attributes significantly affected entrepreneurial performance, the 34 personality attributes were factor-analysed, using principal component analysis with orthogonal VARIMAX rotation, to identify underlying factors. The extraction of the factors and the variables were based on the eigenvalues and the factor loadings of the variables. Eigenvalues are calculated and used in deciding the number of factors to extract in the overall factor analysis. McMillan and Schumacher (2010) proposed dropping factors whose eigenvalues are less than 1 because they provide less information than is provided by a single variable. Only factors with an eigenvalue larger than 1 and attributes with loading larger than 0.50 were considered. The exploratory factor analysis extracted five factors, which accounted for $85 \%$ of variance in the data. Table 3 illustrates the results of this VARIMAX process.

Reliability analysis (Cronbach's alpha) was calculated to test the reliability and internal consistency of each factor. The results of the reliability analysis showed that the Cronbach's alpha coefficients of the extracted factors ranged from 0.7680 to 0.8864 . That is well above the minimum value of 0.60 , which is considered acceptable as an indication of scale reliability (Leedy \& Ormrod 2013). These values suggest good internal consistency of the factors. Finally, the Cronbach's alpha value for the overall entrepreneurial performance scale is 0.8166 and indicates its high reliability.

Most of the factor loadings were greater than 0.60, implying a reasonably high correlation between extracted factors and their individual items (McMillan \& Schumacher 2010). However, three items had factor loadings less than 0.50 and were therefore excluded from the study, leaving 31 items.

TABLE 3: Factor and reliability analysis results of the personality attributes affecting entrepreneurial performance.

\begin{tabular}{|c|c|c|c|c|c|c|}
\hline \multirow[t]{2}{*}{ Items } & \multicolumn{5}{|c|}{ Factors } & \multirow[t]{2}{*}{ Communalities } \\
\hline & F1 & F2 & F3 & F4 & F5 & \\
\hline Broad-minded & 0.790 & - & - & - & - & 0.659 \\
\hline Imaginative & 0.664 & - & - & - & - & 0.808 \\
\hline Sensitive & 0.816 & - & - & - & - & 0.525 \\
\hline Intelligent & 0.735 & - & - & - & - & 0.713 \\
\hline Curious & 0.829 & - & - & - & - & 0.736 \\
\hline Original & 0.723 & - & - & - & - & 0.684 \\
\hline Creative & 0.642 & - & - & - & - & 0.860 \\
\hline Organised & - & 0.867 & - & - & - & 0.631 \\
\hline Systematic & - & 0.717 & - & - & - & 0.547 \\
\hline Purposeful & - & 0.621 & - & - & - & 0.602 \\
\hline Determined & - & 0.684 & - & - & - & 0.700 \\
\hline Dependable & - & 0.756 & - & - & - & 0.658 \\
\hline Friendly & - & - & 0.700 & - & - & 0.666 \\
\hline Cheerful & - & - & 0.595 & - & - & 0.703 \\
\hline Outspoken & - & - & 0.832 & - & - & 0.484 \\
\hline Sociable & - & - & 0.743 & - & - & 0.748 \\
\hline Courteous & - & - & - & 0.839 & - & 0.680 \\
\hline Forgiving & - & - & - & 0.702 & - & 0.589 \\
\hline Soft-hearted & - & - & - & 0.653 & - & 0.692 \\
\hline Affable & - & - & - & 0.651 & - & 0.551 \\
\hline Tolerant & - & - & - & 0.720 & - & 0.674 \\
\hline Trusting & - & - & - & 0.704 & - & 0.829 \\
\hline Kind & - & - & - & 0.789 & - & 0.701 \\
\hline Anxious & - & - & - & - & 0.671 & 0.814 \\
\hline Aggressive & - & - & - & - & 0.735 & 0.596 \\
\hline Temperamental & - & - & - & - & 0.798 & 0.618 \\
\hline Insecure & - & - & - & - & 0.666 & 0.857 \\
\hline Eigenvalue & 6.152 & 3.613 & 6.295 & 4.601 & 3.279 & 23.940 \\
\hline Percentage of variance & 23.276 & 11.003 & 28.634 & 13.742 & 8.610 & 85.265 \\
\hline Cronbach's alpha & 0.8259 & 0.7680 & 0.8864 & 0.7892 & 0.8133 & 0.8166 \\
\hline Number of items & 7 & 5 & 6 & 7 & 6 & - \\
\hline
\end{tabular}


The communalities of 31 items ranged from 0.484 to 0.860 , indicating that a large amount of variance was extracted by the factor solution. The five personality factors identified by VARIMAX as reliable and consistent with an eigenvalue greater than 1 are as follows.

Factor 1: Openness to experience had seven attributes that accounted for $23.28 \%$ of the variance, with an eigenvalue of 6.15 and an alpha coefficient of 0.8259 . This factor included the following attributes: broad-minded, imaginative, sensitive, intelligent, curious, original and creative.

Factor 2: Conscientiousness had five attributes that accounted for $11 \%$ of the variance, with an eigenvalue of 3.61 and an alpha coefficient of 0.7680 . This factor included the following attributes: organised, systematic, purposeful, determined and dependable.

Factor 3: Extraversion had six attributes that accounted for $28.63 \%$ of the variance, with an eigenvalue of 6.30 and an alpha coefficient of 0.8864 . This factor included the following attributes: friendly, warm, assertive, cheerful, outspoken and sociable.

Factor 4: Agreeableness had seven attributes that accounted for $13.74 \%$ of the variance, with an eigenvalue of 4.60 and an alpha coefficient of 0.7892 . This factor included the following attributes: courteous, forgiving, soft-hearted, affable, tolerant, trusting and kind.

Factor 5: Neuroticism had six attributes that accounted for $8.61 \%$ of the variance, with an eigenvalue of 3.28 and an alpha coefficient of 0.8133 . This factor included the following attributes: anxious, aggressive, temperamental, insecure, moody and depressed.

The five orthogonal factors (conscientiousness, agreeableness, openness to experience, extraversion and neuroticism) were used in Pearson's product-moment correlation coefficient and regression analysis to investigate the relationship of overall entrepreneurial performance (dependent variable) with the five personality dimensions (independent variables). The results of the correlation analysis are depicted in Table 4.

The data revealed that three factors, namely conscientiousness, openness to experience and extraversion, significantly $(p<0.05)$ and positively affected entrepreneurial performance, whilst neuroticism significantly $(p<0.05)$ and negatively affected entrepreneurial performance. However, agreeableness did not

TABLE 4: Correlation results of personality dimensions and overall entrepreneurial performance.

\begin{tabular}{lcc}
\hline Personality dimensions & \multicolumn{2}{c}{ Overall entrepreneurial performance } \\
\cline { 2 - 3 } & $\begin{array}{c}\text { Correlation coefficient } \\
(\boldsymbol{r})\end{array}$ & $\begin{array}{c}\text { Significance } \\
(\boldsymbol{p})\end{array}$ \\
\hline Conscientiousness & 0.83 & $<0.0001^{*}$ \\
Agreeableness & 0.62 & 0.1604 \\
Openness to experience & 0.89 & $<0.0001^{*}$ \\
Extraversion & 0.74 & $<0.0001^{*}$ \\
Neuroticism & -0.56 & $<0.0001^{*}$ \\
\hline
\end{tabular}

*, Indicates a significant difference $(p<0.05)$. have any significant effect $(p<0.05)$ on entrepreneurial performance. The personality trait with the highest and most positive effect on entrepreneurial performance was openness to experience $(r=0.89)$, followed by conscientiousness $(r=0.83)$ and extraversion $(r=0.74)$.

The findings on extraversion, conscientiousness and openness to experience significantly and positively affecting entrepreneurial performance are consistent with meta-analytical results presented by Leutner et al. (2014) and Duval et al. (2012). According to Duval et al., entrepreneurs with these traits are more likely to be successful in small businesses because of their creativity prowess.

The findings that agreeableness does not significantly affect entrepreneurial performance contradicts results from previous research scholars (Brandstätter 2011; Ciavarella et al. 2004; Martin et al. 2016; Schröder et al. 2011) who found agreeableness to be a valid predictor of entrepreneurial performance. It seems that being soft-hearted and tolerant (Barrick \& Mount 2005) does not impact on entrepreneurial performance in the hospitality subsector.

A full regression model was run for the dependent variable (entrepreneurial performance). The model regressed the five personality dimensions against overall entrepreneurial performance. The regression model is depicted in Table 5.

The regression model depicted in Table 5 shows that three factors, namely openness to experience $(p<0.0001)$, conscientiousness $(p=0.0124)$ and extraversion $(p=0.086)$, significantly $(p<0.05)$ and positively affected entrepreneurial performance, whilst neuroticism significantly $(p<0.05)$ and negatively affected entrepreneurial performance. However, agreeableness $(p=0.4835)$ did not have any effect on entrepreneurial performance. The $t$-values in Table 5 indicate the relative effect of each factor on the performances of hospitality entrepreneurs. Openness to experience $(t=17.81)$ was rated by respondents as the personality trait that highly and most positively affected entrepreneurial performance, followed by conscientiousness $(t=14.05)$.

From the preceding points, the more open the entrepreneur is, the higher the likelihood of success. A possible explanation is that people high in openness to experience are highly adaptable to change, seem to thrive in situations that require flexibility and are highly motivated to learn new skills. Their open-mindedness leads them to address existing methods for doing business, which in addition to their intellectual

TABLE 5: Regression results of personality dimensions and overall entrepreneurial performance.

\begin{tabular}{lcc}
\hline Independent variables & Model: Overall entrepreneurial performance \\
\cline { 2 - 3 } & $\boldsymbol{t}$-value & $\boldsymbol{p}$ \\
\hline Conscientiousness & 14.05 & $0.0124^{*}$ \\
Agreeableness & 7.61 & 0.4835 \\
Openness to experience & 17.81 & $0.0001^{*}$ \\
Extraversion & 8.24 & $0.0086^{*}$ \\
Neuroticism & -2.13 & $0.0001^{*}$ \\
\hline
\end{tabular}

*, Indicates significant relation $(p<0.05)$. 
capacities results in them recognising new opportunities (Patel \& Thatcher 2014). This reasoning may explain the positive relationship between openness to experience and entrepreneurial performance. In fact, previous literature (see works by Patel \& Thatcher 2014; Slavec 2014) does demonstrate a positive relationship between openness to experience and entrepreneurial performance.

The findings that conscientiousness significantly and positively affected entrepreneurial performance contradicts results from previous research scholars (Leutner et al. 2014; Nadkarni \& Herrmann 2010) who found that conscientiousness negatively affected entrepreneurial performance. It is therefore interesting to speculate why previous studies suggest that conscientiousness negatively affected entrepreneurial performances whereas this study suggests otherwise. A possible explanation might be different industries investigated. It seems in the hospitality subsector, conscientiousness has a positive effect on entrepreneurial performance, unlike the retail and textile industries investigated by Leutner et al. (2014) and Nadkarni and Herrmann (2010), respectively.

The findings further reveal a negative relationship between neuroticism and entrepreneurial performance. These findings support previous literature (Ciavarella et al. 2004; Kaczmarek \& Kaczmarek-Kurczak 2016; Nadkarni \& Herrmann 2010; Zhao et al. 2010), which found the same results. Neurotic individuals are prone to mood swings, are emotionally unstable, highly excitable and self-conscious (Weiten 2010), which negatively affects their entrepreneurial behaviour. Neuroticism has a tendency to reduce risk-taking inclination, thus reducing the willingness to persist in business (Zhao et al. 2010).

The model $F$-value was calculated at $23.94(p<0001)$. The five personality dimensions had a coefficient determination $\left(R^{2}\right)$ of 0.8527 (Table 3) and thus explained more than $85 \%$ of the variability in overall entrepreneurial performance. This explanation of the variability in overall entrepreneurial performance is high when compared to other studies. For example, the regression results of a study performed by Thal and Bedingfield (2010) identified openness to experience, conscientiousness, extraversion and agreeableness as significant factors $(p<0.05)$ affecting entrepreneurial performance, which explained only $66 \%$ of entrepreneurial performance.

\section{Limitations}

Firstly, the use of convenience sampling introduces a source of potential bias into the study, as the risk of unintentionally getting responses from a particular group is higher. For example, few entrepreneurs who are more extraverted, open to experience and agreeable may possibly be more willing to participate in a survey than those who do not have these personality traits. Secondly, the research was based on the effects of personality traits on entrepreneurial performance in the Eastern Cape province. Caution is therefore required when generalising the findings of this study to entrepreneurs in other geographic areas, as a replication of this study in other geographic areas might reveal different results. Lastly, the effects of personality traits on entrepreneurial performance was limited to five personality traits. Even though these traits were included in other studies as well, there could be other relevant personality traits that are likely to affect entrepreneurial performance.

\section{Conclusion and managerial implications}

The purpose of this research endeavour was to identify personality traits affecting entrepreneurial performance in the hospitality subsector. The study clearly indicates that different personality traits have different effects on entrepreneurial performance. As such, extraversion, conscientiousness and openness to experience significantly $(p<0.05)$ and positively affected entrepreneurial performance whilst neuroticism significantly $(p<0.05)$ and negatively affected entrepreneurial performance. However, openness to experience was rated by respondents as the personality trait that highly and most positively affected entrepreneurial performance.

Despite some evidence that agreeableness is a valid predictor of entrepreneurial performance among certain industries, this study contradicts previous studies that agreeableness affects entrepreneurial performance in the hospitality subsector. It appears that being 'nice' is not a necessity for entrepreneur performance in the hospitality subsector. This study provides evidence that personality traits affecting entrepreneurial performance differ from industry to industry and seem to be industry specific. Therefore, it is the author's contention that entrepreneurs from different industries do not share the same personality profile.

To increase entrepreneurs' performance in the hospitality subsector, entrepreneurs should focus on the traits that positively impact on entrepreneurial performance, namely openness to experience and conscientiousness. It could therefore be suggested that being open to novel experiences and ideas and being imaginative, innovative and creative (openness to experience), as well as being hardworking and achievement oriented (conscientiousness), are the personality dimensions that positively impact on entrepreneurial performance in the hospitality subsector.

The results have some theoretical and practical implications for existing and future entrepreneurs. Although personality traits are found to remain stable over an individual's lifetime, and as such are not easily developed, existing entrepreneurs would do well to develop these traits as far as possible. Where personality traits cannot be developed or changed, entrepreneurs could employ people with personality traits that complement their own to assist them in managing their enterprises. Consequently, by identifying the personality traits affecting entrepreneurial performances, proactive steps can be made to identify individuals who are likely to be successful entrepreneurs in the hospitality subsector. 
With the high failure rate of hospitality entrepreneurs in South Africa, there has been increasing interest in determining personality traits that affect entrepreneurial performance in South Africa. The acquisition of this knowledge would provide quantitative support for the premise that entrepreneurs are distinct groups of people and is crucial for aspiring entrepreneurs to understand the psychological nuances of entrepreneurship in the hospitality subsector in South Africa. The study contributes to the ongoing debate concerning personality traits affecting entrepreneurial performance and adds value to literature on entrepreneurship in South Africa, as this is a developing market that is untapped in terms of research and development. The research supports the strategic objectives of the Department of Trade and Industry (2018) to create a vibrant and competitive small enterprise sector with enterprises that grow in both turnover and employment.

\section{Acknowledgements Competing interests}

The author declares that he has no financial or personal relationships that may have inappropriately influenced him in writing this article.

\section{References}

Amir, F., Naz, F., Hafeez, S.Q., Ashfaq, A. \& Dogar, Y.H., 2014, 'Measuring the effect of five factor model of personality on team performance with moderating role of employee engagement', Journal of Psychology and Behavioural Science 2(2), 221-255.

Barrick, M.R. \& Mount, M.K., 2005, 'Yes, personality matters: Moving on to more important matters', Human Performance 18(5), 359-372. https://doi.org/10.1207/ s15327043hup1804_3

Barrick, M.R., Mount, M.K. \& Gupta, R., 2003, 'Meta-analysis of the relationship between five factor model of personality and Holland's occupational types', Personnel Psychology 56(2), 45-74. https://doi.org/10.1111/j.1744-6570.2003. tb00143.x

Barringer, B.R. \& Ireland, R.D., 2010, Entrepreneurship: Successfully launching new venture, Global Edition, 3rd edn., Pearson Education Inc., Upper Saddle River, NJ.

Brandstätter, H., 2011, 'Personality aspects of entrepreneurship: A look at five metaanalyses', Personality and Individual Differences 9(5), 222-230. https://doi. org/10.1016/j.paid.2010.07.007

Ciavarella, M.A., Buchholtz, A.K., Riordan, C.M., Gatewood, R.D. \& Stokes, G.S., 2004 'The big five and venture survival: Is there a linkage?', Journal of Business Venturing 19(6), 465-483. https://doi.org/10.1016/j.jbusvent.2003.03.001

Culture, Arts, Tourism, Hospitality and Sports Sector Education and Training Authority (CATHSSETA), 2018, Tourism and sport skills audit, Sandton, Tourism, Hospitality and Sport Education and Training Authority, Johannesburg, South Africa.

Department of Trade and Industry (DTI), 2018, Strategies to improve entrepreneurship in South Africa, viewed 26 April 2018, from http://www.thedti.gov.za

Duval, T.S., Silvia, P.J. \& Lalwani, N., 2012, Self-awareness and causal attribution A dual systems theory, 3rd edn., Springer Science and Business Media., Berlin Germany.

Erdheim, J., Wang, M. \& Zickar, M.J., 2006, 'Linking the big five personality constructs to organizational commitment', Personality and Individual Differences 41(5), 959-970. https://doi.org/10.1016/j.paid.2006.04.005

Farrington, S.M., 2012, 'Does personality matter for small business success?', South African Journal of Economic and Management Sciences 15(4), 382-401. https:// doi.org/10.4102/sajems.v15i4.243

Isaac, S. \& Michael, W.B., 1981, Handbook in research and evaluation, 2 nd edn., Edits Publishers, San Diego, CA
Kaczmarek, M. \& Kaczmarek-Kurczak, P., 2016, 'Personality traits and self-efficacy as predictors of business performance: A longitudinal study', Annals of Psychology 9(4), 121-137. https://doi.org/10.18290/rpsych.2016.19.1-4en

Kickul, J. \& Neuman, G., 2000, 'Emergent leadership behaviours: The function of personality and cognitive ability in determining teamwork performance', Journal of Business and Psychology 15(1), 27-51. https://doi.org/10.1023/ A 1007714801558

Leedy, P.D. \& Ormrod, J.E., 2013, Practical research: Planning and design, 10th edn., Pearson Education Inc., Upper Saddle River, NJ.

Leutner, F., Ahmetoglu, G., Akhtar, R. \& Chamorro-Premuzic, T., 2014, 'The relationship between the entrepreneurial personality and the Big Five personality traits', Personality and individual differences 7(4), 58-63. https://doi.org/10.1016/j. paid.2014.01.042

Martin, M.B., Julius, F.K. \& Grace, M.K., 2016, 'Does personality of owners of micro enterprises matter for the relationship between start-up capital and entrepreneurial success?', African Journal of Business Management 10(1), 13-23. https://doi.org/10.5897/ÁJBM2015.7738

McMillan, J.H. \& Schumacher, S., 2010, Research in education, 7th edn., Pearson Education Inc., Upper Saddle River, NJ.

Mhlanga, O., 2013, 'Expectations and experiences of customers in formal full service restaurants in Port Elizabeth', African Journal for Physical, Health Education, Recreation and Dance 19(2), 313-323.

Mhlanga, O., 2018a, 'Factors impacting restaurant efficiency: A data envelopment analysis, Tourism Review 73(1), 82-93. https://doi.org/10.1108/TR-07-20170109.

Mhlanga, O., 2018b, 'Customer experiences and return patronage in airport hotels: Evidence from OR Tambo International Airport, South Africa', Acta Commercil 18(1), 1-11. https://doi.org/10.4102/ac.v18i1.471

Mhlanga, O. \& Tichaawa, T.M., 2016, 'Guest expectations and experiences within selected hotels in Nelspruit, Mpumalanga Province of South Africa', African Journal for Physical Activity and Health Sciences 22(4:1), 1185-1197.

Nadkarni, S. \& Herrmann, P., 2010, 'CEO performance, strategic flexibility, and firm performance: The case of the Indian business process outsourcing industry' Academy of Management Journal 53(5), 1050-1073. https://doi.org/10.5465/ amj.2010.54533196

Norman, W.T., 1963, 'Towards an adequate taxonomy of personality attributes: Replicated factor structure in peer nomination personality ratings', The Journal of Abnormal and Social Psychology 66, 574-583.

Patel, P.C. \& Thatcher, S.M., 2014, 'Sticking it out individual attributes and persistence in self-employment', Journal of Management 40(7), 1932-1979. https://doi. org/10.1177/0149206312446643

Said, E., 2013, 'Personality traits and performance: The mediating role of adaptive behaviour in call centres', American Journal of Industrial and Business Management 3(1), 17-27. https://doi.org/10.4236/ajibm.2013.31003

Scarborough, N.M., 2011, Essentials of entrepreneurship and small business management: Global edition, 6th edn., Pearson Education Inc., Upper Saddle River, NJ.

Schröder, E., Schmitt, R.E. \& Arnaud, N., 2011, 'Career choice intentions of adolescents with a family business background', Family Business Review 24(4), 305-321. https://doi.org/10.1177/0894486511416977

Slavec, A., 2014, 'Determinants of SME performance: The effect of entrepreneurial openness and goals', 7th international scientific conference, Economic and Socia Development, New York, pp. 645-652, 6-10 April, 2014.

Small Enterprise Development Agency (SEDA), 2018, 'Analysis of the Needs, State and Performance of Small and Medium Businesses in the Agriculture, Manufacturing, ICT and Tourism Sectors in South Africa', viewed 06 December 2018, from http:// www.seda.org.za/AboutUs/Pages/DSBD.aspx

Srivastava, S., 2010, Measuring the big five personality factors, viewed 31 January 2010, from http//www.uroregon.edu/-sanjay/bigfive.html

Statistics South Africa (SSA), 2018, Food and beverages, March 2018, Statistics South Africa, Pretoria.

Thal, A.E. \& Bedingfield, J.D., 2010, 'Successful project managers: An exploratory study into the impact of personality', Technology Analysis and Strategic Management 22(2), 243-259. https://doi.org/10.1080/09537320903498587

Weiten, W., 2010, Psychology: Themes and variations, Wadsworth Cengage Learning, Belmont, CA, USA.

World Travel and Tourism Council (WTTC), 2018, Travel and tourism economic impact summary, viewed 19 April 2018, from http://www.wttc.org/bin/pdf/tempo/execsummary-final.htm

Zhao, H., Seibert, S.E. \& Lumpkin, G.T., 2010, 'The relationship of personality to entrepreneurial intentions and performance: A meta-analytic review', Journal of Management 36(2), 381-404. https://doi.org/10.1177/0149206309335187 